\title{
[gw22-e0870] A STUDY ON THE RELATIONSHIP BETWEEN PLASMA FIBRINOGEN LEVER AND CORONARY HEART DISEASE IN PATIENTS WITH THE METABOLISM SYNDROME
}

Qiao Ping, Wu zhong, Ma jianlin, Su zhetan, Wu ming Department of Cardiology, Hainan Provincial Hospital, Hainan, China

10.1136/heartjnl-2011-300867.414

Objective To study the relationship between plasma fibrinogen lever and coronary heart disease in patients with the metabolism syndrome.

Methods The plasma fibrinogen lever was measured in 107 patients with the metabolism syndrome, involving 57 cases of coronary heart disease (CHD), and compared with 42 normal subjects (control).

Results Plasma fibrinogen levels of patients with the metabolism syndrome were significantly higher than control group $(p<0.01)$. Plasma fibrinogen levels of CHD group with the metabolism syndrome were higher than noth CHD group with the metabolism syndrome.

Conclusion The plasma fibrinogen lever maybe a risk factor of CHD in the metabolism syndrome. 